\title{
Discapacidad y universidad española: protección del estudiante universitario en situación de discapacidad ${ }^{* *}$
}

\section{Disability and Spanish University: Protection of university students with disabilities}

SUMARIO

I. Aproximación conceptual a la discapacidad. II. El derecho a la educación universitaria y la discapacidad. II.1. El derecho a la educación superior en España previamente a la Convención sobre los Derechos de las Personas con Discapacidad, celebrada en Nueva York el 13 de diciembre de 2006. a. Ley 13/1982, de 7 de abril, de integración social de los minusválidos. b. Normas Uniformes sobre Igualdad de Oportunidades para las Personas con Discapacidad. c. Ley Orgánica 6/2001, de 21 de diciembre, de Universidades. II.2. El derecho a la educación superior en España desde la Convención sobre los Derechos de las Personas con Discapacidad, celebrada en Nueva York el 13 de diciembre de 2006, hasta la actualidad. a. La Convención sobre los Derechos de las Personas con Discapacidad. b. Modificaciones normativas en materia de educación universitaria derivadas de la Convención sobre los Derechos de las Personas con Discapacidad. III. Medidas de acción positiva, implementación de las disposiciones normativas a la vista de varios informes sobre la situación de las universidades españolas en materia de discapacidad. IV. Reflexión.

\section{RESUMEN}

El derecho a la educación es un derecho fundamental internacionalmente reconocido. Empero, este reconocimiento está condicionado a las circunstancias personales del valedor o tenedor del mismo. Nos encontramos ante un

* Tamara Álvarez Robles, Personal Docente Investigador en formación, Área de Derecho Constitucional. Universidad de León. Contacto: talvr@unileon.es

** Recibido el 12 de noviembre de 2015, aprobado el 16 de mayo de 2016.

Para citar el artículo: T. ÁLVAREZ RoBLES, Discapacidad y Universidad española: protección del estudiante universitario en situación de discapacidad, Derecho del Estado n. ${ }^{\circ}$ 36, Universidad Externado de Colombia, enero-junio de 2016,3-39. DoI: http://dx.doi.org/10.18601/01229893.n36.01. 
derecho doblemente importante debido a que no sólo hablamos de educación en el sentido de ser receptor de una enseñanza sino también de integración y participación en la sociedad, de ahí que se promueva la implicación de todos los poderes públicos para su implementación y desarrollo.

La evolución de tal derecho hasta la Convención sobre los Derechos de las Personas con Discapacidad, celebrada en Nueva York el 13 de diciembre de 2006, momento en el cual se consolida la implicación de la comunidad internacional a este respecto, se ha visto confrontada en la actualidad en razón de la crisis económica que se está viviendo el último tiempo. De ahí que el motivo del presente estudio sea reivindicar la necesidad de implantación y aplicación de la normativa en materia de discapacidad en las universidades mediante la reforma de sus normas y la formación e información del personal.

La universalización de los derechos, como la educación, se topa con dificultades para lograr su plenitud en cuanto los titulares del mismo presentan diferencias con respecto a otros receptores de este derecho. El reto de este trabajo es visualizar la situación en un entorno muy específico, el de la enseñanza universitaria, y en un contexto muy preciso, el del Reino de España. Sin embargo, la globalización hace asumir como propios los principales problemas y retos que se identifican en este trabajo.

Se repara en el carácter prolijo de una legislación que tiene su origen e impulso en el ámbito internacional, para recalar en el ordenamiento interno con un grado de desarrollo y dispersión que chocan con una clara efectividad. La existencia de una voluntad meridiana de las autoridades competentes en adoptar un modelo inclusivo choca con dificultades exógenas, especialmente la carencia de medios, pero también endógenas, como la falta de implicación de alguno de los actores afectados. Desde estas líneas se afronta la necesidad de ser más rigurosos en la implementación de unos objetivos, que desde la letra de la ley son atrayentes y loables.

\section{PALABRAS CLAVE}

Derecho a la educación, discapacidad, igualdad, integración social.

\section{ABSTRACT}

Right to education is a fundamental right, internationally recognized. However, this assumption is conditioned by personal circumstances, details, of the holder. In any case, we should emphasize the double dimension of this, firstly the right to receive education/teaching, secondly its consideration as a channel of integration and social participation. It is due to this situation, the involvement of the public powers, in order to implement and develop of this right, must be promoted. 
The application of the right to education to people that suffer disabilities has got a great degree of importance under The Convention on the Rights of Persons with Disabilities, held in New York in December 2006. At that time the international community implications were really consolidated. This situation has changed dramatically with the economic crisis that we are suffering in recent times. This is the main reason for the present study, an appeal to implement and apply regulation about disabilities at University studies trough the reform of their statutes and by the increase of the level of the information and training of their workers, especially professors.

The universalization of rights, such as education, faces difficulties in achieving its fullness as all holders differ with respect to other recipients of this right. The challenge of this work is to visualize the situation in a very specific environment, university education, and in a very precise context that is the Kingdom of Spain. However, globalization should assume ownership the main problems and challenges identified in this work.

It will be checked in the prolix character of legislation that rules the right af everyone, although you were different to be the holder of the right to education. The existence of a huge number of authorities who supports an inclusive model collides with exogenous difficulties, especially the lack of means, but also endogenous, as the lack of involvement of any of the actors involved. From these lines need to be more rigorous in implementing objectives is facing, that since the letter of the law are attractive and praiseworthy

\section{KEYWORDS}

Right to education, disability, equality, social integration.

\section{APROXIMACIÓN CONCEPTUAL A LA DISCAPACIDAD}

El concepto de discapacidad ha evolucionado al mismo ritmo que lo han hecho los derechos aplicados al colectivo de personas discapacitadas, pudiendo evidenciarse dicha transición en la normativa objeto de aplicación.

De este modo, si comenzamos por revisar la Constitución Española de 1978 , en su precepto 49 encontramos el término discapacidad referido a un ámbito de asistencia, siguiendo el modelo médico o rehabilitador, propio del momento en el cual fue positivado el texto constitucional español:

Los poderes públicos realizarán una política de previsión, tratamiento, rehabilitación e integración de los disminuidos físicos, sensoriales y psíquicos, a los que prestarán la atención especializada que requieran y los ampararán especialmente para el disfrute de los derechos que este Título otorga a todos los ciudadanos. 
Este artículo $49 \mathrm{CE}-42^{[1]}$ en el anteproyecto de la Constitución-, encargado de la tutela de las personas con discapacidad, apenas supondría debates en sede parlamentaria, al contrario, sería aprobado sin inconvenientes, a falta de un cambio en su redacción - pasando de "Los poderes públicos garantizarán..." a "Los poderes públicos realizarán una política de previsión, tratamiento, rehabilitación e integración..."-, cierto es que existieron votos particulares, como el del Grupo Socialista ${ }^{2}$, en la misma dirección, esto es, por la modificación en la redacción.

Previsión, tratamiento, rehabilitación e integración, atención especializada y amparo para el disfrute de derechos especialmente del Título I, entre los que se encuentra el derecho a la educación del artículo 27, son las principales notas características de una aproximación al término discapacidad en su vertiente médico-asistencial contemplada en el citado artículo $49 \mathrm{CE}$.

A partir de la década de 1980 este concepto comienza a evolucionar más allá de la perspectiva asistencial; ejemplo de ello será la resolución aprobada por la Asamblea General de las Naciones Unidas, en su cuadragésimo octavo periodo de sesiones, de 20 de diciembre de 1993, encargado de dar forma a lo que denominaría "Normas Uniformes sobre Igualdad de Oportunidades para las Personas con Discapacidad" ${ }^{3}$. En esta se toma como referencia al Año Internacional de los Impedidos (1981), del cual derivaría el Programa de Acción Mundial para los Impedidos, aprobado el 3 de diciembre de 1982 en la Resolución 7/42 de la Asamblea General de las Naciones Unidas que define por primera vez la discapacidad como función de relación entre las personas con discapacidad y su entorno. Si bien en la Resolución A/RES/48/96 se diferencia la discapacidad ${ }^{4}$ del concepto de minusvalía ${ }^{5}$, en cuanto a que

1 Anteproyecto de Constitución Española: Boletín Oficial de las Cortes de 5 de enero de 1978, n. ${ }^{\circ} 44$. Artículo 42: "Los poderes públicos garantizarán a los disminuidos físicos o mentales y personas incapacitadas una atención especializada y un reforzamiento del amparo que los derechos fundamentales de este título otorgan a todos los ciudadanos".

2 Ibíd. "Artículo 42. Voto particular de modificación de la frase '... a los disminuidos físicos o mentales y personas incapacitadas...' por '... a los disminuidos físicos, mentales o sensoriales y personas incapacitadas...".

3 Disponible en: http://www.un.org/spanish/disabilities/default.asp?id=498

4 Resolución A/REs/48/96: “17. Con la palabra 'discapacidad' se resume un gran número de diferentes limitaciones funcionales que se registran en las poblaciones de todos los países del mundo. La discapacidad puede revestir la forma de una deficiencia física, intelectual o sensorial, una dolencia que requiera atención médica o una enfermedad mental. Tales deficiencias, dolencias o enfermedades pueden ser de carácter permanente o transitorio".

5 Resolución A/RES/48/96: "18. Minusvalía es la pérdida o limitación de oportunidades de participar en la vida de la comunidad en condiciones de igualdad con los demás. La palabra 'minusvalía' describe la situación de la persona con discapacidad en función de su entorno. Esa palabra tiene por finalidad centrar el interés en las deficiencias de diseño del entorno físico y de muchas actividades organizadas de la sociedad, por ejemplo, información, comunicación y educación, que se oponen a que las personas con discapacidad participen en condiciones de igualdad". 
con discapacidad se alude a un gran número de limitaciones de tipo funcional, mientras, por su parte, la minusvalía supondría la pérdida o limitación de oportunidades de participación en la vida, describiendo la situación de la persona con discapacidad.

El concepto de discapacidad hace referencia a la persona que posee una limitación funcional, bien sea permanente o transitoria, derivada de una deficiencia, dolencia o enfermedad; se sigue manteniendo en cierto grado esa vinculación asistencial o médica del término; si bien el de minusvalía se refiere al entorno que limita la participación de la persona.

Un ejemplo del progreso o devenir subsiguiente sería el que se recoge en la Convención sobre los Derechos de las Personas con Discapacidad celebrada en Nueva York el 13 de diciembre de 2006:

... la discapacidad es un concepto que evoluciona y que resulta de la interacción entre las personas con deficiencias y barreras debidas a la actitud y al entorno que evitan su participación plena y efectiva en la sociedad en igualdad de condiciones con los demás. [...] Las personas con discapacidad incluyen aquellas personas que tengan deficiencias físicas, mentales, intelectuales o sensoriales a largo plazo que, al interactuar con diversas barreras, puedan impedir su participación plena y efectiva en la sociedad, en igualdad de condiciones que los demás.

Evoluciona el término discapacidad en cuanto a su perdurabilidad -"largo plazo"- y su interacción con el entorno y la sociedad -"barreras", "actitud"-. Podemos decir que se produce, en cierto grado, una fagocitación del término minusvalía, anteriormente referido, así como la superación de la perspectiva médico-asistencial que venía manteniendo el citado concepto, en pro de la afección de ciertos derechos y/o principios como pueden ser la participación o la igualdad.

Esta misma idea se recoge en la Ley 26/2011, de 1 de agosto, de adaptación normativa a la Convención Internacional sobre los Derechos de las Personas con Discapacidad, la cual aborda el citado término desde una perspectiva basada en los derechos humanos:

La discapacidad queda configurada como la circunstancia personal y el ecosistema social resultante de la interacción del hecho diferencial de algunas personas con un entorno inadecuado por excluyente en tanto en cuanto que establecido según el parámetro de persona "normal".

Esta tiene en cuenta un cómputo de circunstancias, no sólo personales y sociales sino del propio entorno, que excluye y/o limita a la persona del disfrute de derechos y libertades, y que como la misma ley contempla puede suponer un agravante a esa situación dada. De este modo, la discapacidad no es tanto de la persona sino que también se traslada al entorno; la persona padece una 
deficiencia, en cualquiera de los supuestos contemplados, pero es el entorno excluyente el que la "dis-capacita" para el disfrute de sus derechos.

En todo caso esta Ley 26/2011 modifica, entre otras, a la Ley 51/2003, de 2 de diciembre, de igualdad de oportunidades, no discriminación y accesibilidad universal de las personas con discapacidad; y lo hace precisando qué se entiende por discapacidad a los efectos de la misma:

Son personas con discapacidad aquellas que presenten deficiencias físicas, mentales, intelectuales o sensoriales a largo plazo que, al interactuar con diversas barreras, puedan impedir su participación plena y efectiva en la sociedad, en igualdad de condiciones con los demás. [...] a los efectos de esta ley, tendrán la consideración de personas con discapacidad aquellas a quienes se les haya reconocido un grado de discapacidad igual o superior al 33 por ciento. En todo caso, se consideran que presentan una discapacidad en grado igual o superior al 33 por ciento los pensionistas de la Seguridad Social que tengan reconocida una pensión de incapacidad permanente en grado de total, absoluta o gran invalidez y a los pensionistas de clases pasivas que tengan reconocida una pensión de jubilación o de retiro por incapacidad permanente para el servicio o inutilidad.

El concepto de discapacidad, como acabamos de ver, en ocasiones precisa de un complemento, esto es, no es suficiente con que la persona padezca una circunstancia personal/disfunción, que la misma sea a largo plazo, que en su interactuación con el entorno vea mermados sus derechos porque el mismo sea excluyente, sino que se precisa del reconocimiento/certificación de un grado mínimo para hacer efectivos según qué derechos. En el caso de la normativa española suele establecerse el 33\% como regla genérica y la asimilación a prestaciones por incapacidad de Seguridad Social, en los términos que acabamos de ver.

Referido a la cuestión del largo plazo esta circunstancia es matizada en el Real Decreto 1/2013, de 29 de noviembre, por el que se aprueba el Texto Refundido de la Ley General de derechos de las personas con discapacidad y su inclusión social, la cual se refiere a la discapacidad en los siguientes términos:

1. Son personas con discapacidad aquellas que presentan deficiencias físicas, mentales, intelectuales o sensoriales, previsiblemente permanentes que, al interactuar con diversas barreras, puedan impedir su participación plena y efectiva en la sociedad, en igualdad de condiciones con los demás.

2. Además de lo establecido en el apartado anterior, y a todos los efectos, tendrán la consideración de personas con discapacidad aquellas a quienes se les haya reconocido un grado de discapacidad igual o superior al 33 por ciento. Se considerará que presentan una discapacidad en grado igual o superior al 33 por ciento los pensionistas de la Seguridad Social que tengan reconocida una pensión de 
incapacidad permanente en el grado de total, absoluta o gran invalidez, y a los pensionistas de clases pasivas que tengan reconocida una pensión de jubilación o de retiro por incapacidad permanente para el servicio o inutilidad.

Las normas que regulen los beneficios o medidas de acción positiva podrán determinar los requisitos específicos para acceder a los mismos.

En este caso se establece la previsión del largo plazo, quedando regulados el resto de los requisitos en los términos que se venían observando.

Con todo ello, varias son las características que hemos de entender para hablar de una persona con discapacidad en el ámbito de la educación superior o universitaria y que influirán en el disfrute de los derechos a los mismos reconocidos. Así, no es suficiente padecer una deficiencia, en cualquiera de las modalidades contenidas (física, mental, intelectual o sensorial), sino que esta ha de ser padecida previsiblemente a largo plazo, ha de estar reconocida conforme al reglamento en cuestión (en la mayoría de los supuestos), al interactuar con un entorno ha de impedir la participación plena y efectiva, constituyendo las diferentes barreras, y debe limitar o afectar al principio de igualdad.

Como vemos, una suma de circunstancias o factores hará que tome efectividad el artículo 9.2 $\mathrm{CE}^{6}$ y actúen los poderes públicos, en este caso conforme al derecho a la educación, en cuanto a una serie de derechos y/o principios que se encuentran en estrecha relación con el citado derecho, como pueden ser la igualdad, la no discriminación, la accesibilidad y la participación.

\section{EL DERECHO A LA EDUCACIÓN UNIVERSITARIA Y LA DISCAPACIDAD}

El derecho a la educación es un derecho fundamental ${ }^{7}$, reconocido internacionalmente $^{8}$ a todas las personas, si bien con diferentes matices en función de la circunstancia personal del tenedor o valedor del derecho, pero en todo caso un derecho doblemente importante ya que no sólo se habla de

6 Art. 9.2 CE: "Corresponde a los poderes públicos promover las condiciones para que la libertad y la igualdad del individuo y de los grupos en que se integra sean reales y efectivas; remover los obstáculos que impidan o dificulten su plenitud y facilitar la participación de todos los ciudadanos en la vida política, económica, cultural y social".

7 STC 236/2007, de 7 de noviembre, FJ 8: "Es inequívoca la vinculación del derecho a la educación con la garantía de la dignidad humana, dada la trascendencia que aquélla adquiere para el pleno y libre desarrollo de la personalidad, y para la misma convivencia en sociedad, que se ve reforzada mediante la enseñanza de los valores democráticos y el respeto a los derechos humanos, necesarios para establecer una sociedad democrática avanzada".

8 Declaración Universal de los Derechos Humanos (DUDH); Pacto Internacional de Derechos Civiles y Políticos; Protocolo Adicional al Convenio para la Protección de los Derechos Humanos y de las Libertades Fundamentales, de 20 de marzo de 1952; Carta de Derechos Fundamentales de la Unión Europea (CDFUE), etc. 
educación ${ }^{9}$ en el sentido de ser receptor de una enseñanza sino también de integración y participación en la sociedad, como es defendido por el Tribunal Constitucional ${ }^{10}$; de ahí que se promueva la implicación de todos los poderes públicos para su desarrollo e implementación. Si fijamos nuestra atención en el colectivo de personas discapacitadas, la norma que prevalece es la enseñanza "general" frente a la "especial" 1 , siendo esta última accesoria en caso de que la enseñanza general no esté preparada o bien no sea adecuada para la persona, existiendo así mismo limitaciones ${ }^{12}$, que serán desarrolladas posteriormente. Es por ello que el presente trabajo tiene por objeto el estudio de la normativa reguladora de la enseñanza universitaria general relativa a las personas con discapacidad.

9 En este sentido: Moswela, E. y Mukhopadhyay, S. (2011). Asking for too much? the voices of students with disabilities in botswana. Disability \& Society, 26(3), 307-319. Dor: 10.1 080/09687599.2011.560414

10 STC 10/2014, de 27 de enero, FJ 4: “... Para analizar esta cuestión debemos tener presente el marco normativo específico sobre el derecho a la educación de las personas con discapacidad, constituido por el art. $27 \mathrm{CE}$, que reconoce el derecho de todos a la educación, el art. $14 \mathrm{CE}$ que prohíbe 'discriminación alguna' por 'cualquier circunstancia o condición personal' y el art. 49 $\mathrm{CE}$ que, sin reconocer derechos fundamentales, sí ordena a los poderes públicos realizar una política de integración de los discapacitados. Estos preceptos, como este Tribunal ha venido afirmando desde la temprana STC 38/1981, de 23 de noviembre, FJ 4, han de ser interpretados, en virtud del art. 10.2 CE, a la luz de lo dispuesto en los tratados internacionales que España haya celebrado sobre la materia...".

11 Así queda recogido ya en el año 1993 con las Normas Uniformes sobre Igualdad de Oportunidades para las Personas con Discapacidad (A/RES/48/96), en su artículo sexto apartado octavo: "En situaciones en que el sistema de instrucción general no esté aún en condiciones de atender las necesidades de todas las personas con discapacidad, cabría analizar la posibilidad de establecer la enseñanza especial, cuyo objetivo sería preparar a los estudiantes para que se educaran en el sistema de enseñanza general. La calidad de esa educación debe guiarse por las mismas normas y aspiraciones que las aplicables a la enseñanza general y vincularse estrechamente con ésta. Como mínimo, se debe asignar a los estudiantes con discapacidad el mismo porcentaje de recursos para la instrucción que el que se asigna a los estudiantes sin discapacidad. Los Estados deben tratar de lograr la integración gradual de los servicios de enseñanza especial en la enseñanza general. Se reconoce que, en algunos casos, la enseñanza especial puede normalmente considerarse la forma más apropiada de impartir instrucción a algunos estudiantes con discapacidad".

12 STC 10/2014, de 27 de enero, FJ 4: “... De la normativa anterior se desprende como principio general que la educación debe ser inclusiva, es decir se debe promover la escolarización de los menores en un centro de educación ordinaria, proporcionándoseles los apoyos necesarios para su integración en el sistema educativo si padecen algún tipo de discapacidad. En definitiva, la Administración educativa debe tender a la escolarización inclusiva de las personas discapacitadas y tan sólo cuando los ajustes que deba realizar para dicha inclusión sean desproporcionados o no razonables, podrá disponer la escolarización de estos alumnos en centros de educación especial. En este último caso, por respeto a los derechos fundamentales y bienes jurídicos afectados, en los términos que hemos expuesto anteriormente, dicha Administración deberá exteriorizar los motivos por los que ha seguido esta opción, es decir por qué ha acordado la escolarización del alumno en un centro de educación especial por ser inviable la integración del menor discapacitado en un centro ordinario...". 
El derecho a la educación, en España, se encuentra regulado en el artículo 27 de la Constitución Española de 1978 ${ }^{[13]}$, configurándose como derecho fundamental, si bien este es completado y perfeccionado por diferente normativa supranacional y nacional a la hora de referirnos al colectivo de personas con discapacidad. No obstante, sin salirnos de la Carta Magna, hemos de conectarlo en este momento con el artículo 9.2 CE, anteriormente señalado, el cual contiene un mandato, a los poderes públicos, para remover los obstáculos que dificulten la igualdad y participación plena y efectiva en este supuesto del colectivo de discapacitados. Junto a ambos preceptos, se puede completar el derecho a la educación con el artículo 49 CE, en el cual el legislador quiso proteger el disfrute de los derechos del Título I, entre los cuales se encuentra el citado derecho, si bien explicitado para el colectivo referido. Este artículo 49 contiene dos postulados, el principio de igualdad material (contemplado en el art. 9.2 CE), al hablar de políticas de previsión, tratamiento, rehabilitación e integración; y un principio en su vertiente negativa, pues se trata de la prohibición de la discriminación (contemplado en el art. $14 \mathrm{CE}$ ), al establecer que los poderes públicos amparan especialmente a las personas con discapacidad para el disfrute de los derechos del Título I.

En suma, hemos de tener en cuenta que al referirnos al derecho a la educación, en el ámbito universitario o de educación superior, este no sólo se refiere al concepto de educación stricto sensu, sino también al disfrute de la vida y de las actividades derivadas de la Universidad, al entorno universitario; de este modo hemos de tener presente la pluralidad de niveles normativos en función de las distintas competencias afectadas, así como la evolución que las diferentes normas irán sufriendo, a medida que nos aproximamos al

13 Art. 27 CE: "1. Todos tienen el derecho a la educación. Se reconoce la libertad de enseñanza.

2. La educación tendrá por objeto el pleno desarrollo de la personalidad humana en el respeto a los principios democráticos de convivencia y a los derechos y libertades fundamentales.

3. Los poderes públicos garantizan el derecho que asiste a los padres para que sus hijos reciban la formación religiosa y moral que esté de acuerdo con sus propias convicciones.

4. La enseñanza básica es obligatoria y gratuita.

5. Los poderes públicos garantizan el derecho de todos a la educación, mediante una programación general de la enseñanza, con participación efectiva de todos los sectores afectados y la creación de centros docentes.

6. Se reconoce a las personas físicas y jurídicas la libertad de creación de centros docentes, dentro del respeto a los principios constitucionales.

7. Los profesores, los padres y, en su caso, los alumnos intervendrán en el control y gestión de todos los centros sostenidos por la Administración con fondos públicos, en los términos que la ley establezca.

8. Los poderes públicos inspeccionarán y homologarán el sistema educativo para garantizar el cumplimiento de las leyes.

9. Los poderes públicos ayudarán a los centros docentes que reúnan los requisitos que la ley establezca.

10. Se reconoce la autonomía de las Universidades, en los términos que la ley establezca”. 
ciudadano, pudiendo observar una mayor concreción en cuanto a medidas de acción positiva o plazos.

II.1. El derecho a la educación superior en España previamente

a la Convención sobre los Derechos de las Personas con Discapacidad, celebrada en Nueva York el 13 de diciembre de 2006

Como mencionamos con anterioridad, en 1981 tuvo lugar el Año Internacional de los Impedidos, dando lugar a un impulso normativo tanto a nivel internacional como nacional, entre otros, del derecho a la educación de las personas con discapacidad; empero, nosotros fijaremos nuestra atención en el ámbito universitario; de ese modo podremos profundizar y detenernos en el estudio del derecho mencionado.

\section{a. Ley 13/1982, de 7 de abril, de integración social de los minusválidos}

A nivel nacional podemos resaltar la Ley 13/1982, de 7 de abril, de integración social de los minusválidos (LISMI) ${ }^{14}$, que si bien presenta ese carácter prestacional o médico-asistencial derivado de la previsión constitucional, no es menos cierto que comienza una apertura tendente a la consideración de los principios y derechos de los mismos, pues en ella dedica la sección tercera "De la educación", que comprende los artículos 23 a 31 (ambos inclusive), al tratamiento del colectivo de personas discapacitadas en el ámbito de la educación. En esta sección se recoge ese carácter preferente de la educación general ${ }^{15}$, así como se dedica un apartado específico, concretamente en su artículo 31.2, a la Universidad, en los siguientes términos:

Los minusválidos que cursen estudios universitarios cuya minusvalía les dificulte gravemente la adaptación al régimen de convocatorias establecido con carácter general, podrán solicitar y los centros habrán de conceder la ampliación del número de las mismas en la medida que compense su dificultad. Sin mengua del nivel exigido, las pruebas se adaptarán, en su caso, a las características de la minusvalía que presente el interesado.

14 Alonso Seco, J. M. et al. (1992). Desarrollo y aplicación de la LISMI (1982-1992) (2. a ed.). Madrid: Secretaría General del Real Patronato de Prevención y de Atención a personas con Minusvalía.

15 Se considera a la educación especial como algo transitorio, preferiblemente, o permanente, si no es posible ese carácter transitorio: Ley 13/1982, de 7 de abril, de integración social de los minusválidos, artículo veintitrés "Uno. El minusválido se integrará en el sistema ordinario de la educación general, recibiendo, en su caso, los programas de apoyo y recursos que la presente Ley reconoce.

Dos. La Educación Especial será impartida transitoria o definitivamente, a aquellos minusválidos a los que les resulte imposible la integración en el sistema educativo ordinario y de acuerdo con lo previsto en el artículo veintiséis de la presente Ley”. 
De este precepto se derivan dos cuestiones importantes, la adaptación del régimen de convocatorias en función de las necesidades de la persona discapacitada, disminuida en términos de la ley ${ }^{16}$, y la exigencia de un nivel mínimo a tener en consideración, como límite a ese derecho y que como veremos aún en la actualidad es recogido por la normativa de desarrollo, configurando uno de los pocos límites al disfrute del derecho a la educación general en la enseñanza superior.

Esta norma, garante de la integración social y la realización personal del discapacitado así como de los principios de normalización y atención individualizada, estaría en vigor, de forma parcial, hasta el 4 de diciembre de 2013, derogándose por Real Decreto Legislativo 1/2013, de 29 de noviembre, por el que se aprueba el Texto Refundido de la Ley General de derechos de las personas con discapacidad y de su inclusión social, si bien en lo referente al objeto de estudio no sería objeto de reforma o derogación expresa.

\section{b. Normas Uniformes sobre Igualdad de Oportunidades para las Personas con Discapacidad}

El impulso a nivel internacional quedaría reflejado, entre otras muchas actuaciones, en la resolución de la Asamblea General de las Naciones Unidas llevada a cabo el 20 de diciembre de 1993, por la cual se establecen las Normas Uniformes sobre Igualdad de Oportunidades para las Personas con Discapacidad, en la que se contempla el derecho a la educación en su artículo 6 desde la base del principio de la igualdad de oportunidades ${ }^{17}$.

Estas normas o pautas, aunque no se trate de un instrumento jurídicamente vinculante por sí solo, sí son importantes en cuanto afectan al compromiso en las políticas públicas llevadas a cabo por los distintos gobiernos, así como al devenir de la legislación que pueda derivarse de los aspectos en las mismas contemplados, como queda explicitado en el texto:

Aunque no son de cumplimiento obligatorio, estas Normas pueden convertirse en normas internacionales consuetudinarias cuando las aplique un gran número de Estados con la intención de respetar una norma de derecho internacional. Llevan

16 Ley 13/1982, de 7 de abril, de integración social de los minusválidos, artículo siete: "Uno. A los efectos de la presente Ley se entenderá por minusválidos toda persona cuyas posibilidades de integración educativa, laboral o social se hallen disminuidos como consecuencia de una deficiencia, previsiblemente permanente, de carácter congénito o no, en sus capacidades físicas, psíquicas o sensoriales".

17 Normas Uniformes sobre la igualdad de oportunidades para las personas con discapacidad (A/RES/48/96), artículo 6. Educación: "Los Estados deben reconocer el principio de la igualdad de oportunidades de educación en los niveles primario, secundario y superior para los niños, los jóvenes y los adultos con discapacidad en entornos integrados, y deben velar por que la educación de las personas con discapacidad constituya una parte integrante del sistema de enseñanza". 
implícito el firme compromiso moral y político de los Estados de adoptar medidas para lograr la igualdad de oportunidades. Se señalan importantes principios de responsabilidad, acción y cooperación. Se destacan esferas de importancia decisiva para la calidad de vida y para el logro de la plena participación y la igualdad. Estas Normas constituyen un instrumento normativo y de acción para personas con discapacidad y para sus organizaciones. También sientan las bases para la cooperación técnica y económica entre los Estados, las Naciones Unidas y otras organizaciones internacionales.

De este modo, y para que se produzca la integración de las personas con discapacidad en el sistema de enseñanza, se establecen una serie de medidas ${ }^{18}$ que han de ser implementadas por los Estados y entre las cuales destacamos las siguientes:

- Política claramente formulada, comprendida y aceptada.

- Planes de estudio flexibles y adaptables.

- Provisión de materiales didácticos de calidad.

- Formación constante del personal docente y de apoyo.

En el apartado octavo del artículo 6, dedicado a la educación, se ratifica la predilección por la enseñanza general, siempre y cuando sea posible, frente a la especial. Conteniendo el mandato de integración gradual de los servicios de la enseñanza especial en la enseñanza general.

Así mismo, en esta norma se establece un apartado que habla de la responsabilidad y de la obligación ${ }^{19}$ correspondiente a la persona discapacitada a medida que esta logra la igualdad de oportunidades, de forma casi excepcional en comparación con el resto de la normativa objeto de estudio.

18 Normas Uniformes sobre la igualdad de oportunidades para las personas con discapacidad (A/REs/48/96), artículo 6.6: "Para que las disposiciones sobre instrucción de personas con discapacidad puedan integrarse en el sistema de enseñanza general, los Estados deben:

Contar con una política claramente formulada, comprendida y aceptada en las escuelas y por la comunidad en general;

Permitir que los planes de estudio sean flexibles y adaptables y que sea posible añadirles distintos elementos según sea necesario;

Proporcionar materiales didácticos de calidad y prever la formación constante de personal docente y de apoyo".

19 Ibíd. Introducción. Conceptos fundamentales de la política relativa a la discapacidad. Logro de la igualdad de oportunidades: "27. A medida que las personas con discapacidad logren la igualdad de derechos, deben también asumir las obligaciones correspondientes. A su vez, con el logro de esos derechos, las sociedades pueden esperar más de las personas con discapacidad. Como parte del proceso encaminado a lograr la igualdad de oportunidades deben establecerse disposiciones para ayudar a esas personas a asumir su plena responsabilidad como miembros de la sociedad". 


\section{c. Ley Orgánica 6/2001, de 21 de diciembre, de Universidades}

La conciliación de ambas normas tendrá cierto grado de inclusión en la Ley Orgánica 6/2001, de 21 de diciembre, de Universidades, en cuyos preceptos se promulgan principios y valores tan importantes como la igualdad de oportunidades y la no discriminación ${ }^{20}$, configurándolos como derechos del alumno, los cuales habrían de ser desarrollado estatutariamente. En todo caso, igualdad y no discriminación en el acceso, en la permanencia y en el ejercicio de derechos desde la base de las directrices de dos leyes ${ }^{21}$, Ley 13/1982, de 7 de abril, de Integración Social de los Minusválidos, y Ley Orgánica 1/1990, de 3 de octubre, de Ordenación General del Sistema Educativo. La Ley Orgánica 6/2001 supondría el punto de partida para muchos estatutos de las universidades que recogerían o incorporarían alguna referencia a la discapacidad, si bien de manera muy somera, normalmente remitiéndose a la legalidad vigente y conteniendo los principios de igualdad y no discriminación.

Tras la observación de estas breves notas normativas, estos primeros pasos hacia el desarrollo normativo/legal de los derechos que acompañan al estudiante universitario con discapacidad, hemos de reconocer que no se tiene un gran recelo a la hora de normar y establecer medidas de acción positiva en esta primera etapa, que comprenderá los años anteriores a la Convención sobre los Derechos de las Personas con Discapacidad celebrada en Nueva York en 2006; la parte más extensa de las diferentes normas será dedicada al cuidado de tipo médico-asistencial, reconociendo tan sólo la predilección por una enseñanza general y el trato igualitario y no discriminatorio una vez que los mismos se encuentran dentro de esa generalidad en el ámbito de la educación superior.

20 Ley Orgánica 6/2001, de 21 de diciembre, de Universidades, artículo 46. Derechos y deberes de los estudiantes: " 2 . Los Estatutos y normas de organización y funcionamiento desarrollarán los derechos y los deberes de los estudiantes, así como los mecanismos para su garantía. En los términos establecidos por el ordenamiento jurídico, los estudiantes tendrán derecho a: b) La igualdad de oportunidades y no discriminación, por circunstancias personales o sociales, incluida la discapacidad, en el acceso a la Universidad, ingreso en los centros, permanencia en la Universidad y ejercicio de sus derechos académicos".

21 Ibíd. Disposición adicional vigésima cuarta: "De la integración de estudiantes con discapacidad en las Universidades. Las Universidades en el desarrollo de la presente Ley tendrán en cuenta las disposiciones de la Ley 13/1982, de 7 de abril, de Integración Social de los Minusválidos, y Ley Orgánica 1/1990, de 3 de octubre, de Ordenación General del Sistema Educativo, en lo referente a la integración de estudiantes con discapacidades en la enseñanza universitaria, así como en los procesos de selección de personal al que se refiere la presente Ley". 


\section{II.2. El derecho a la educación superior en España desde la Convención sobre los Derechos de las Personas con Discapacidad, celebrada en Nueva York el 13 de diciembre de 2006, hasta la actualidad}

\section{a. La Convención sobre los Derechos de las Personas con Discapacidad}

La Convención (de la Asamblea General de las Naciones Unidas) sobre los Derechos de las Personas con Discapacidad, celebrada en Nueva York el 13 de diciembre de $2006^{[22]}$, supuso un punto de inflexión a la hora de abordar los diferentes aspectos del colectivo de personas con discapacidad, convirtiéndose en un instrumento jurídico completamente válido, el cual, en el momento de ratificación por parte de los diferentes Estados firmantes, obliga a su cumplimiento y observancia. En este sentido, España firma el mismo el 30 de marzo de $2007^{[23]}$ y lo ratifica el 21 de abril de 2008, entrando en vigor el 3 de mayo de 2008 tras su publicación en el Boletín Oficial del Estado ${ }^{24}$, momento a partir del cual pasa a formar parte del ordenamiento jurídico español, derecho positivo, conforme al artículo 96 CE.

La Convención establece una serie de principios $^{25}$ que habrán de ser respetados en todos los ámbitos y que guiarán las diferentes políticas públicas de los Estados parte: el respeto a la dignidad inherente a la persona, la autonomía individual, la no discriminación, la participación e inclusión plenas y efectivas, la igualdad de oportunidades o la accesibilidad, completando los principios y valores previamente contemplados por la normativa internacional y nacional. Así como obliga a los Estados a adoptar todas las medidas legislativas, administrativas y de otra índole que sean necesarias para implementar, para hacer efectivos los derechos que en la Convención se contienen. Nos encontramos ante una norma de mínimos ${ }^{26}$ que podrá ser fortalecida por los Estados y que en todo caso se aplicará a la totalidad del territorio ${ }^{27}$ del Estado parte.

22 El 13 de diciembre de 2006 la Asamblea General de las Naciones Unidas aprueba, por consenso, la Convención sobre los Derechos de las Personas con Discapacidad así como el Protocolo facultativo de la misma.

23 Si bien su tramitación parlamentaria sería la siguiente: el 18 de octubre de 2007 se procede a su aprobación por el Congreso, remitiéndose al Senado, donde se aprobaría el 6 de noviembre de 2007; tras ello fue ratificado por el Rey el 23 de noviembre de 2007.

24 BOE n..$^{\circ}$ 96, de 21 de abril de 2008, 20648-20659.

25 Principios Generales que se recogerán en el artículo 3 de la misma.

26 Convención sobre los Derechos de las Personas con Discapacidad, artículo 4.4: "Nada de lo dispuesto en la presente Convención afectará a las disposiciones que puedan facilitar, en mayor medida, el ejercicio de los derechos de las personas con discapacidad y que puedan figurar en la legislación de un Estado Parte o en el derecho internacional en vigor en dicho Estado...".

27 Ibíd., artículo 4.5: "Las disposiciones de la presente Convención se aplicarán a todas las partes de los Estados federales sin limitaciones ni excepciones". 
En España, en lo relativo al derecho a la educación universitaria de las personas con discapacidad, se produce un interés y desarrollo por parte del legislador, el cual, como veremos, irá adquiriendo cada vez más compromisos que atañerán o incumbirán a todos los ámbitos territoriales implicados en el desempeño o afectación de la prestación del derecho a la educación en su sentido más amplio, esto es, en cuanto a la regularización del derecho contenido en el artículo $27.10 \mathrm{CE}^{28}$ y al reparto competencial ${ }^{29}$, destacando los artículos 148 y $149 \mathrm{CE}$ y en especial el $149.1 .30^{\mathrm{a}} \mathrm{CE}^{30}$.

La Convención dedica el artículo 24 al derecho a la educación, estableciendo dos principios fundamentales e indisponibles: "la no discriminación" y "la igualdad de oportunidades", así como indica a los Estados que habrán de crear un sistema educativo inclusivo (en todos los niveles). De este modo las personas discapacitadas, participando de manera real y efectiva, desarrollarán plenamente su potencial, su dignidad y autoestima, así como su personalidad, y los Estados garantizarán que no queden excluidos del sistema educativo general por razón de discapacidad, garantizando por el contrario el respeto del principio de igualdad de oportunidades, en el acceso ${ }^{31}$, permanencia y disfrute de sus derechos en el ámbito de la educación.

Es importante señalar que en la Convención, para hacer efectivo el artículo 24 , se establece una serie de medidas entre las que destacamos textualmente, por su relación con la Universidad ${ }^{32}$, las siguientes:

“- Se hagan ajustes razonables en función de las necesidades individuales;

- Se preste el apoyo necesario a las personas con discapacidad, en el marco del sistema general de educación, para facilitar su formación efectiva;

28 Artículo 27.10 CE: "Se reconoce la autonomía de las Universidades, en los términos que la ley establezca".

29 SSTC 5/1981; 6/1982; 77/1985; 14/2004; 111/2012; 214/2012.

30 Artículo 149.1: "El Estado tiene competencia exclusiva sobre las siguientes materias: [...] 30. Regulación de las condiciones de obtención, expedición y homologación de títulos académicos y profesionales y normas básicas para el desarrollo del artículo 27 de la Constitución, a fin de garantizar el cumplimiento de las obligaciones de los poderes públicos en esta materia".

31 Convención sobre los Derechos de las Personas con Discapacidad, Preámbulo: "v) Reconociendo la importancia de la accesibilidad al entorno físico, social, económico y cultural, a la salud y la educación y a la información y las comunicaciones, para que las personas con discapacidad puedan gozar plenamente de todos los derechos humanos y las libertades fundamentales".

32 Ibíd., artículo 24.5: "Los Estados Partes asegurarán que las personas con discapacidad tengan acceso general a la educación superior, la formación profesional, la educación para adultos y el aprendizaje durante toda la vida sin discriminación y en igualdad de condiciones con las demás. A tal fin, los Estados Partes asegurarán que se realicen ajustes razonables para las personas con discapacidad". 
- Se faciliten medidas de apoyo personalizadas y efectivas en entornos que fomenten al máximo el desarrollo académico y social, de conformidad con el objetivo de la plena inclusión.

- Facilitar el aprendizaje del Braille, la escritura alternativa, otros modos, medios y formatos de comunicación aumentativos o alternativos y habilidades de orientación y de movilidad, así como la tutoría y el apoyo entre pares;

- Facilitar el aprendizaje de la lengua de señas y la promoción de la identidad lingüística de las personas sordas".

Se refiere este artículo 24 al concepto de ajustes razonables ${ }^{33}$, ajustes que habrán de ser llevados a cabo para la prestación del derecho a la educación en la Universidad. Este concepto ha de ser entendido, en virtud del artículo 2 de la Convención, en los siguientes términos:

Por "ajustes razonables" se entenderán las modificaciones y adaptaciones necesarias y adecuadas que no impongan una carga desproporcionada o indebida, cuando se requieran en un caso particular, para garantizar a las personas con discapacidad el goce o ejercicio, en igualdad de condiciones con las demás, de todos los derechos humanos y libertades fundamentales.

Para que este derecho pueda ser disfrutado desde la base de la igualdad y la no discriminación hemos de conectarlo con otras previsiones de la Convención; de este modo el estudiante universitario discapacitado podrá desarrollarse no sólo como estudiante sino como persona, siendo parte esencial de la sociedad, mediante el disfrute de varios derechos. Nos referimos, entre otros, al derecho de participación en la vida pública, cultural o deportiva, derechos a los cuales la Convención les dedica un espacio, los artículos 29 y 30 principalmente, obligando de ese modo a los Estados a tomar medidas que promuevan la participación plena y efectiva y la igualdad de condiciones.

En este sentido, hemos seleccionado aquellas previsiones que interaccionan con el sistema universitario superior:

“- Su participación en organizaciones y asociaciones no gubernamentales relacionadas con la vida pública;

- La constitución de organizaciones de personas con discapacidad que representen a estas personas a nivel internacional, nacional, regional y local, y su incorporación a dichas organizaciones;

33 CAyo Pérez Bueno, L. "La configuración jurídica de los ajustes razonables", disponible en: www.coag.es 
- Acceso a material cultural, programas de televisión, películas, teatro y otras actividades culturales en formatos accesibles;

- Acceso a lugares en donde se ofrezcan representaciones o servicios culturales tales como teatros, museos, cines, bibliotecas y servicios turísticos y que, en la medida de lo posible, tengan acceso a monumentos y lugares de importancia cultural nacional, instalaciones deportivas, recreativas y turísticas;

- Alentar y promover la participación, en la mayor medida posible, de las personas con discapacidad en las actividades deportivas generales a todos los niveles;

- Asegurar que las personas con discapacidad tengan la oportunidad de organizar y desarrollar actividades deportivas y recreativas específicas para dichas personas y de participar en dichas actividades y, a ese fin, alentar a que se les ofrezca, en igualdad de condiciones con las demás, instrucción, formación y recursos adecuados".

Por lo tanto, atendemos a diferentes cuestiones, recogidas en la Convención, que afectan al estudiante universitario discapacitado: desde el acceso a edificios públicos ${ }^{34}$, pasando por el derecho a la educación ${ }^{35}$, hasta llegar a la plena integración y participación ${ }^{36}$ de los asuntos públicos, sociales, culturales y deportivos. Si bien para lograr la consecución de estas metas no será suficiente con la implicación del Estado, sino que se necesitará el compromiso y la cooperación internacional ${ }^{37}$, ad extra, y la concienciación o toma de conciencia ${ }^{38}$, ad intra.

34 Cuya previsión, la accesibilidad, se recoge en el artículo noveno de la Convención.

35 Así se complementará el artículo $27 \mathrm{CE}$ con el 24 de la Convención.

36 Participación conforme a los artículos 9.2, 23, 43.3 y 44 CE.

37 En este sentido la Convención dedica su artículo 32: "Los Estados Partes reconocen la importancia de la cooperación internacional y su promoción, en apoyo de los esfuerzos nacionales para hacer efectivos el propósito y los objetivos de la presente Convención, y tomarán las medidas pertinentes y efectivas a este respecto, entre los Estados y, cuando corresponda, en asociación con las organizaciones internacionales y regionales pertinentes y la sociedad civil, en particular organizaciones de personas con discapacida". Proponiendo así mismo una serie de medidas de cooperación.

38 Toma en conciencia de la sociedad para sensibilizarla, para que se rompa con los estereotipos y se respeten los derechos y la dignidad de las personas discapacitadas, y donde tendrá un importantísimo papel el sistema educativo en todos sus niveles, como consagra el artículo octavo de la Convención. 


\section{b. Modificaciones normativas en materia de educación universitaria derivadas de la Convención sobre los Derechos de las Personas con Discapacidad}

Las disposiciones contenidas en la Convención entraron en vigor el 3 de mayo de 2008; sin embargo sería observada con anterioridad a su entrada en vigor. Cabe preguntarse cómo se han incorporado e implementado en España las consideraciones legislativas, las medidas y acciones en la misma indicadas, con respecto al ámbito universitario.

\section{La Ley Orgánica 4/2007, de 12 de abril, por la que se modifica la Ley Orgánica 6/2001, de 21 de diciembre, de Universidades}

La Ley Orgánica 4/2007, de 12 de abril, por la que se modifica la Ley Orgánica 6/2001, de 21 de diciembre, de Universidades (en adelante LO 4/2007), da cumplimiento a las indicaciones de la Convención mediante la introducción y el impulso de políticas activas que garantizan la accesibilidad del entorno universitario así como la igualdad de oportunidades a las personas con discapacidad que se encuentran en la Universidad. Lo hace de forma expresa mostrando de ese modo su apoyo a las personas discapacitadas, y con necesidades especiales, en preceptos como el 45.4, relativo a la política de becas, ayudas y créditos, al disponer que "se prestará especial atención a las personas con [...] discapacidad, garantizando así su acceso y permanencia a los estudios universitarios"; se establece por lo tanto la concepción de un sistema público de ayudas complementarias del que participan todos los niveles administrativos, tanto el Estado, como las Comunidades Autónomas y las propias universidades, estableciéndose también la exención total o parcial de los precios públicos en el supuesto de las universidades públicas. Junto a ello, el artículo 46.2.b, relativo a los derechos de los estudiantes, establece "La igualdad de oportunidades y no discriminación [...] en el acceso a la universidad, ingreso en los centros, permanencia en la universidad y ejercicio de sus derechos académicos"; y fundamentalmente, en la modificación de la disposición adicional 24, artículo 90 LO 4/2007, relativa a la inclusión de las personas con discapacidad en las universidades, establece: "1. Las universidades garantizarán la igualdad de oportunidades de los estudiantes y demás miembros de la comunidad universitaria con discapacidad, proscribiendo cualquier forma de discriminación y estableciendo medidas de acción positiva tendentes a asegurar la participación plena y efectiva en el ámbito universitario". Por lo que se garantiza no sólo la no discriminación, el acceso y permanencia a la universidad, sino también la participación.

Las medidas o políticas activas encaminadas al disfrute del derecho a la educación de las personas con discapacidad, así como al deporte y las actividades de extensión universitaria, "aspecto capital en la formación del 
alumnado universitario" 39 , se recogen fundamentalmente en el artículo noventa de la misma, si bien existen otros preceptos que igualmente contienen medidas o previsiones. Podemos agrupar estas políticas o medidas activas en los siguientes grupos:

- Adaptación normativa ${ }^{40}$ : se prevé la adaptación, conforme a los artículos 149.1.30a y 27.10 CE, de las normas básicas de desarrollo; previendo la elaboración, por el Gobierno, de un estatuto del estudiante universitario, así como también la adaptación de los estatutos de las diferentes universidades, en el plazo máximo de tres años.

- Coordinación e información universitaria ${ }^{41}$ : se contempla la necesidad de coordinarse entre las diferentes universidades y dentro de las mismas así como la necesidad de informar de los progresos, medidas implementadas o necesarias, por parte de los distintos órganos universitarios. Se contemplan programas específicos que presten coordinadamente las administraciones públicas competentes para que las personas con discapacidad puedan recibir ayudas, apoyos y adaptaciones.

- Medidas de acción positiva ${ }^{42}$ directas, que han de implementar las universidades, tendentes a lograr la igualdad de oportunidades, la no discriminación y la plena participación: aportación de medios, apoyos y recursos necesarios; accesibilidad de los edificios, instalaciones y dependencias, incluidos los espacios virtuales, conforme a las condiciones y plazos establecidos en la Ley $51 / 2003$, de 2 de diciembre, de igualdad de oportunidades, no discriminación y accesibilidad universal de las personas con discapacidad; adaptación y/o elaboración de planes de estudio que cumplan con el principio de accesibilidad universal y diseño para todos; exención o reducción de tasas y política de becas, subvenciones y créditos.

39 La Ley Orgánica 4/2007, de 12 de abril, por la que se modifica la Ley Orgánica 6/2001, de 21 de diciembre, de Universidades, Preámbulo: "Otro aspecto novedoso es la inclusión de un título dedicado al deporte y la extensión universitaria, pues se considera que tanto el deporte como otras actividades que se contemplan son un aspecto capital en la formación del alumnado universitario".

40 Así consta en el Preámbulo, en el artículo cuarenta y siete y la disposición adicional octava.

41 Mediante la remisión de informes por parte de los órganos de coordinación conforme a las directrices contempladas en el artículo veintisiete que modifica al Título IV "De la coordinación universitaria", resaltando los artículos dedicados a la Conferencia General de Política Universitaria y al Consejo de Universidades. Y la disposición adicional séptima en cuanto a programas específicos de ayuda.

42 Mayoritariamente recogidas en el artículo noventa que modifica la disposición adicional vigésimo cuarta, junto a las disposiciones adicionales cuarta y séptima. 
2. Real Decreto 1791/2010, de 30 de diciembre, por el que se aprueba el Estatuto del Estudiante Universitario

Con motivo de esta modificación de la Ley Orgánica de Universidades, cumpliendo el mandato que se contenía en la misma, tiene lugar la aprobación del Estatuto del Estudiante Universitario mediante Real Decreto 1791/2010, de 30 de diciembre. Empero, tiene su origen en el artículo $27^{[43]}$ apartados 5 y 7 de la Constitución, referidos a la participación en el control y la gestión de los centros. En torno a diecisiete artículos contendrán referencias al colectivo de estudiantes con discapacidad: desde los principios básicos e indisponibles, como la no discriminación (arts. 4 y 13.j), la participación (arts. 38.3.c, 38.5, 62.5 y 64.4), la representación (arts. 35.5 y 36.f), el acceso y admisión (art. 15), hasta medidas concretas como tutorías (art. 22), prácticas académicas (art. 24.4); movilidad (art. 18), pruebas de evaluación (art. 26), comunicación y revisión de calificaciones (arts. 29.2 y 30.2, respectivamente), o la creación de servicios de atención al estudiante (arts. 65 apdos. 5 a 8 y 66.4), son contemplados en el texto.

Si bien, para hacer efectivos estos derechos, en el propio Real Decreto se contempla un precepto, artículo 12 apartado b, que obliga a las universidades a establecer recursos y adaptaciones necesarias para que los estudiantes con discapacidad ejerzan todos los derechos en igualdad de condiciones que el resto, con un único límite, la no disminución del nivel académico exigido.

\section{Ley 26/2011, de 1 de agosto, de adaptación normativa a la Convención Internacional sobre los Derechos de las Personas con Discapacidad}

La Ley 26/2011, de 1 de agosto, de adaptación normativa a la Convención Internacional sobre los Derechos de las Personas con Discapacidad, tiene por objeto dar cumplimiento a las previsiones de la Convención, más allá de lo que ya se venía produciendo; encuentra su fundamento en el artículo 4 de la Convención. Se establecen varias prioridades: la reforma o modificación de más de una decena de normas ${ }^{44}$, el compromiso de las adaptaciones estableciendo plazos, y mediante la profundización del modelo social contemplado

43 Artículo 27 apartados 5 y 7 CE: "5. Los poderes públicos garantizan el derecho de todos a la educación, mediante una programación general de la enseñanza, con participación efectiva de todos los sectores afectados y la creación de centros docentes.

7. Los profesores, los padres y, en su caso, los alumnos intervendrán en el control y gestión de todos los centros sostenidos por la Administración con fondos públicos, en los términos que la ley establezca".

44 Modificaciones normativas:

Artículo 1. La Ley 51/2003, de 2 de diciembre, de igualdad de oportunidades, no discriminación y accesibilidad universal de las personas con discapacidad.

Artículo 2. Modificación de la Ley 27/2007, de 23 de octubre, por la que se reconocen las 
en la Ley 51/2003, de 2 de diciembre, de igualdad de oportunidades, no discriminación y accesibilidad universal de las personas con discapacidad (LIONDAU), así como la incorporación de un nuevo supuesto de sanción accesoria $^{45}$ en la Ley 49/2007, de 26 de diciembre, por la que se establece el

lenguas de signos españolas y se regulan los medios de apoyo a la comunicación oral de las personas sordas, con discapacidad auditiva y sordociegas.

Artículo 3. Modificación de la Ley 49/2007, de 26 de diciembre, de infracciones y sanciones en materia de igualdad de oportunidades, no discriminación y accesibilidad universal de las personas con discapacidad.

Artículo 4. Modificación del Texto Refundido de la Ley de Infracciones y Sanciones en el Orden Social, aprobado por Real Decreto Legislativo 5/2000, de 4 de agosto.

Artículo 5.Modificación de la Ley 30/1979, de 27 de octubre, sobre extracción y trasplante de órganos.

Artículo 6. Modificación de la Ley 14/1986, de 25 de abril, General de Sanidad.

Artículo 7. Modificación de la Ley 41/2002, de 14 de noviembre, básica reguladora de la autonomía del paciente y de derechos y obligaciones en materia de información y documentación clínica.

Artículo 8. Modificación de la Ley 14/2006, de 26 de mayo, sobre técnicas de reproducción humana asistida.

Artículo 9. Modificación de la Ley 16/2003, de 28 de mayo, de cohesión y calidad del Sistema Nacional de Salud.

Artículo 10. Modificación de la Ley 44/2003, de 21 de noviembre, de ordenación de las profesiones sanitarias.

Artículo 11. Modificación de la Ley 7/2007, de 12 de abril, del Estatuto Básico del Empleado Público.

Artículo 12. Modificación de la Ley 2/1985, de 21 de enero, sobre Protección Civil.

Artículo 13. Modificación de la Ley 23/1998, de 7 de julio, de Cooperación Internacional para el Desarrollo.

Artículo 14. Modificación de la Ley 50/1980, de 8 de octubre, de Contrato de Seguro.

Artículo 15. Modificación de la Ley 49/1960, de 21 de julio, sobre Propiedad Horizontal.

Artículo 16. Modificación de la Ley 34/2002, de 11 de julio, de servicios de la sociedad de la información y de comercio electrónico.

Artículo 17. Modificación de la Ley 39/2007, de 19 de noviembre, de la carrera militar.

Artículo 18. Modificación de la Ley 30/2007, de 30 de octubre, de Contratos del Sector Público.

Artículo 19. Modificación de la Ley 13/1982, de 7 de abril, de integración social de los minusválidos.

45 Ley 49/2007, de 26 de diciembre, de infracciones y sanciones en materia de igualdad de oportunidades, no discriminación y accesibilidad universal de las personas con discapacidad, artículo 6. Sanciones accesorias: "Cuando las infracciones sean graves o muy graves, los órganos competentes propondrán, además de la sanción que proceda, la prohibición de concurrir en procedimientos de otorgamiento de ayudas oficiales, consistentes en subvenciones o cualesquiera otras ayudas en el sector de actividad, en cuyo ámbito se produce la infracción, por un período máximo de un año, en el caso de las graves, y de dos, en el caso de las muy graves.

Cuando las infracciones sean muy graves, además los órganos competentes propondrán la supresión, cancelación o suspensión total o parcial de ayudas oficiales, consistentes en subvenciones y cualesquiera otras que la persona sancionada tuviese reconocidos en el sector de actividad en cuyo ámbito se produce la infracción.

La comisión de una infracción muy grave por las instituciones que presten servicios sociales podrá conllevar la inhabilitación para el ejercicio de las actividades de cuidado, tanto para personas físicas como jurídicas, por un plazo máximo de cinco años". 
régimen de infracciones y sanciones en materia de igualdad de oportunidades, no discriminación y accesibilidad universal de las personas con discapacidad. Si bien es cierto que no alude expresamente al derecho a la educación ni a la Universidad, afecta al disfrute del mismo en los términos señalados con anterioridad. La adopción de esta norma fue aplaudida por las Naciones Unidas en documento $\mathrm{CRPD} / \mathrm{C} / \mathrm{ESP} / \mathrm{CO} / 1^{[46]}$, en el segundo ${ }^{47}$ de sus apartados relativo a aspectos positivos.

\section{Real Decreto 1276/2011, de 16 de septiembre, de adaptación normativa a la Convención Internacional sobre los Derechos de las Personas con Discapacidad}

El Real Decreto 1276/2011, de 16 de septiembre, de adaptación normativa a la Convención Internacional sobre los Derechos de las Personas con Discapacidad modifica una pluralidad de normas, puesto que su objetivo es adecuar la regulación reglamentaria vigente en materia de discapacidad a las directrices de la Convención, en la línea marcada por la Ley 26/2011, de 1 de agosto, de adaptación normativa a la Convención Internacional sobre los Derechos de las Personas con Discapacidad.

A los efectos que nos interesan, en cuanto al derecho a la educación, varias son las disposiciones que en el mismo se contienen y que nos interesan. Veamos.

El artículo primero, relativo al transporte público, en cuanto a medio de transporte que puede ser utilizado por el estudiante discapacitado para ir a la Universidad. Modificación del Real Decreto 1544/2007, de 23 de noviembre, por el que se regulan las condiciones básicas de accesibilidad y no discriminación para el acceso y utilización de los modos de transporte para personas con discapacidad. "Tiene como finalidad incluir los Planes de Accesibilidad en todos los sectores del transporte y establecer un criterio para deslindar las grandes infraestructuras y servicios de las de pequeña entidad"48.

\footnotetext{
46 Documento disponible en: http://www.un.org/Docs/journal/asp/ws.asp?m=CRPD/C/ESP/ $\mathrm{CO} / 1$

$47 \mathrm{CRPD} / \mathrm{C} / \mathrm{ESP} / \mathrm{CO} / 1$ : "El Comité congratula al Estado parte por los progresos hechos en muchos sectores relacionados con los derechos de las personas con discapacidad, en particular la aprobación de la Ley n. ${ }^{\circ} 26 / 2011$, de $1 .^{\circ}$ de agosto de 2011, sobre la adaptación de las normas a la Convención, la modificación de reglamentos y de varias leyes en respuesta a la Convención, y la adopción de importantes medidas positivas en los sectores de la salud, la vivienda y el empleo y en otras esferas".

48 Exposición de motivos del Real Decreto 1276/2011, de 16 de septiembre, de adaptación normativa a la Convención Internacional sobre los Derechos de las Personas con Discapacidad.
} 
La disposición adicional primera, en cuanto a designación del CERMI ${ }^{49-50}$ como órgano de control y supervisión, controlando a las universidades en la aplicación de la Convención y la normativa en materia de discapacidad.

Designación de mecanismo independiente para promover, proteger y supervisar en España la Convención Internacional sobre los Derechos de las Personas con Discapacidad. Sin perjuicio de las funciones del Defensor del Pueblo como Alto Comisionado para la defensa de los derechos humanos, y a los efectos del número 2 del artículo 33 de la Convención Internacional sobre los Derechos de las Personas con Discapacidad, se designa al Comité Español de Representantes de Personas con Discapacidad (CERMI), en tanto que asociación de utilidad pública más representativa en el ámbito estatal de los diferentes tipos de discapacidad, como mecanismo independiente para promover, proteger y supervisar la aplicación en España del citado Tratado internacional.

La disposición adicional segunda ${ }^{51}$, sobre el suministro de información de las comunidades autónomas. Afectando este suministro de información a las universidades y aquellas administraciones que sin ser universidad tiene implicación en la efectividad del derecho a la educación superior.

De acuerdo con los principios de información mutua y colaboración entre Administraciones públicas y con lo previsto en la Ley Orgánica 15/1999, de 13 de diciembre, de Protección de Datos de Carácter Personal, y con el fin de garantizar el cumplimiento de las obligaciones internacionales, las comunidades autónomas,

49 El CERMI es la plataforma de encuentro y acción política de las personas con discapacidad, constituido por las principales organizaciones estatales de personas con discapacidad, varias entidades adheridas de acción sectorial y un nutrido grupo de plataformas autonómicas, todas las cuales agrupan a su vez a más de 7.000 asociaciones y entidades, que representan en su conjunto a los 3.8 millones de personas con discapacidad que hay en España, un 10\% de la población total. Véase: www.cermi.es

50 Ello fue uno de los aspectos positivos valorados por las Naciones Unidas en el documento CRPD/C/ESP/CO/1, apartado segundo, relativo a los aspectos positivos: "El Comité felicita al Estado parte por el establecimiento de un mecanismo de supervisión independiente en cumplimiento del artículo 33, párrafo 2, de la Convención".

51 De este modo se daría cumplimiento a la obligación específica que contempla el CRPD/C/ ESP/CO/1 en su apartado III C: "49. El Comité lamenta la escasez de datos desglosados sobre las personas con discapacidad. El Comité recuerda que esa información es indispensable para comprender la situación, en el Estado parte, de grupos concretos de personas con discapacidad que tengan diferentes grados de vulnerabilidad; para elaborar leyes, políticas y programas adaptados a la situación de esas personas, y para evaluar la aplicación de la Convención.

50. El Comité recomienda al Estado parte que sistematice la recopilación, el análisis y la difusión de datos desglosados por sexo, edad y discapacidad; que desarrolle la capacidad a este respecto, y que prepare indicadores que tengan en cuenta el género para contribuir a la elaboración de disposiciones legislativas, a la formulación de políticas y al reforzamiento institucional a fin de supervisar los progresos realizados en la aplicación de las diversas disposiciones de la Convención y para preparar informes al respecto". 
en el ámbito de sus competencias, remitirán anualmente y por vía electrónica a la Dirección General de Coordinación de Políticas Sectoriales sobre la Discapacidad del Ministerio de Sanidad, Política Social e Igualdad datos estadísticos sobre la situación de las personas con discapacidad relativos al reconocimiento de grado de discapacidad, movilidad, edad, sexo y datos sobre prestaciones o beneficios reconocidos por las Administraciones autonómicas, así como aquellos otros datos que se acuerden con los órganos competentes de las comunidades autónomas...

\section{Real Decreto Legislativo 1/2013, de 29 de noviembre,} por el que se aprueba el Texto Refundido de la Ley General de derechos de las personas con discapacidad y de su inclusión social

El Real Decreto Legislativo 1/2013, de 29 de noviembre, por el que se aprueba el Texto Refundido de la Ley General de derechos de las personas con discapacidad y de su inclusión social tiene como objetivo la labor de refundición, aclaración y armonización, por mandato de la Ley 26/2011, de varias normas, derogando aquellos preceptos que se opongan a esta y particularmente tres leyes:

- Ley 49/2007, de 26 de diciembre (Ref. Boe-A-2007-22293).

- Ley 51/2003, de 2 de diciembre (Ref. BOE-A-2003-22066).

- Ley 13/1982, de 7 de abril (Ref. BOE-A-1982-9983).

Reitera el compromiso con los principios y mandatos que tanto la Convención como la normativa internacional y nacional contemplan, y en suma dedica su Capítulo iv al derecho a la educación.

En su artículo 18 apartado 1, el primero de los artículos del Capítulo IV, se establecen cuatro mandatos que serán desarrollados a lo largo del texto: la educación ha de ser inclusiva, de calidad, gratuita ${ }^{52}$ y ha de respetarse la igualdad ${ }^{53-54}$ de condiciones. En el apartado segundo del artículo 18 se establecen una serie de garantías ${ }^{55}$ que han de asegurar las administraciones educativas, como son la regulación de apoyos y ajustes razonables en es-

52 Real Decreto Legislativo 1/2013, de 29 de noviembre, por el que se aprueba el Texto Refundido de la Ley General de derechos de las personas con discapacidad y de su inclusión, artículo 19: "Gratuidad de la enseñanza. Las personas con discapacidad, en su etapa educativa, tendrán derecho a la gratuidad de la enseñanza, en los centros ordinarios y en los centros especiales, de acuerdo con lo que disponen la Constitución y las leyes que la desarrollan".

53 Regulando las condiciones básicas de accesibilidad y no discriminación en los artículos 22 y 23 y dedicando su Título II a la "Igualdad de oportunidades y no discriminación".

54 La vulneración del derecho a la igualdad de oportunidades se recoge en el artículo 63 RDL 2/2013 en los siguientes términos: "Se entenderá que se vulnera el derecho a la igualdad de oportunidades de las personas con discapacidad, definidas en el artículo 4.1, cuando, por motivo de o por razón de discapacidad, se produzcan discriminaciones directas o indirectas, discriminación por asociación, acosos, incumplimientos de las exigencias de accesibilidad y de realizar ajustes razonables, así como el incumplimiento de las medidas de acción positiva legalmente establecidas".

55 En este sentido hemos de completar con el Título II, Capítulo I, artículos 65 a 68, que 
pecial en el aprendizaje e inclusión de los estudiantes que precisen de una especial atención.

Y en este sentido, el de ajustes razonables hemos de relacionarlo con la STC 96/2012, FJ 10, en la cual se asienta el criterio del juicio de proporcionalidad:

... para comprobar si una medida restrictiva de un derecho fundamental supera el juicio de proporcionalidad, es necesario constatar si cumple los tres siguientes requisitos o condiciones: si tal medida es susceptible de conseguir el objetivo propuesto (juicio de idoneidad); si, además, es necesaria, en el sentido de que no exista otra medida más moderada para la consecución de tal propósito con igual eficacia (juicio de necesidad); $y$, finalmente, si la misma es ponderada o equilibrada, por derivarse de ella más beneficios o ventajas para el interés general que perjuicios sobre otros bienes o valores en conflicto (juicio de proporcionalidad en sentido estricto).

Que operará junto con la motivación por parte de la Administración en el sentido de la STC 10/2014 FJ 4, 5 y 6:

... dicha Administración deberá exteriorizar los motivos por los que ha seguido esta opción, es decir por qué ha acordado la escolarización del alumno en un centro de educación especial por ser inviable la integración del menor discapacitado en un centro ordinario. [...] explicado convenientemente por qué supone una carga desproporcionada para la Administración la escolarización del menor en un centro ordinario con los apoyos precisos [...] ponderando sus especiales necesidades educativas, y lo hace mediante un razonamiento que supera el juicio de proporcionalidad exigido por nuestra doctrina en aquellos casos en los que la actuación cuestionada de los poderes públicos afecta a un derecho fundamental sustantivo [...] [E]l alumno necesita algo más, mucho más que ajustes razonables respecto a lo que precisan sus compañeros de edad similar; lamentablemente sufre un desfase muy importante desde la primer fase de la educación infantil en la que está, a la educación primaria que le corresponde por edad; y requiere no un aula normal, sino un aula especial muy poco poblada y con una organización de la misma muy pendiente del mismo, incluyendo un sistema de educación diferenciada.

Por lo que no sólo habrá de guiarse esa razonabilidad por las normas contempladas en el presente estudio sino que habrá de cumplir la proporcionalidad y la motivación a la hora de operar respecto al derecho del estudiante discapacitado.

Por último, el apartado tercero reitera la excepcionalidad de la educación especial.

contienen las medidas contra la discriminación y de acción positiva; y Capítulo II, que contempla las medidas de fomento y defensa. 
El Real Decreto Legislativo 1/2013 desarrolla una serie de garantías tendentes a la consecución de la inclusión en el artículo 20, dedicando su apartado c) a las universidades:

Las personas que cursen estudios universitarios, cuya discapacidad les dificulte gravemente la adaptación al régimen de convocatorias establecido con carácter general, podrán solicitar y las universidades habrán de conceder, de acuerdo con lo que dispongan sus correspondientes normas de permanencia que, en todo caso, deberán tener en cuenta la situación de las personas con discapacidad que cursen estudios en la universidad, la ampliación del número de las mismas en la medida que compense su dificultad, sin mengua del nivel exigido. Las pruebas se adaptarán, en su caso, a las características de la discapacidad que presente el interesado.

En este sentido tan sólo se contempla un límite expreso a la adaptación de las convocatorias, y este es el nivel exigido, al igual que lo haría la LISMI (Ley 13/1982). En todo caso los centros de las universidades (facultades, escuelas, etc.) podrán contar con la ayuda de los servicios de las mismas para dar cumplimiento a la inclusión del alumno con discapacidad; así, los servicios tendrán funciones de orientación, evaluación e intervención educativa, contribuyendo a asegurar la integración y la calidad, conforme a lo estipulado en el artículo 21 relativo a la valoración de las necesidades educativas.

Para finalizar, la disposición final segunda alude expresamente a las universidades al hablar de la formación en diseño universal o diseño para todas las personas: "Asimismo, en el caso de las enseñanzas universitarias, el Gobierno fomentará que las universidades contemplen medidas semejantes en el diseño de sus titulaciones".

\section{Real Decreto 412/2014, de 6 de junio, por el que se establece la normativa básica de los procedimientos de admisión a las enseñanzas universitarias oficiales de Grado}

El Real Decreto 412/2014, de 6 de junio, por el que se establece la normativa básica de los procedimientos de admisión a las enseñanzas universitarias oficiales de Grado, recoge, en una serie de preceptos, alusiones al colectivo de estudiantes discapacitados; así desde su artículo $5^{[56]}$ apartados uno y dos

56 Real Decreto 412/2014, de 6 de junio, por el que se establece la normativa básica de los procedimientos de admisión a las enseñanzas universitarias oficiales de Grado, artículo 5. Principios generales de admisión a las enseñanzas universitarias oficiales de Grado:

"1. La admisión a las enseñanzas universitarias oficiales de Grado se realizará con respeto a los principios de igualdad, no discriminación, mérito y capacidad.

2. Todos los procedimientos de admisión a la universidad deberán realizarse en condiciones de accesibilidad para los estudiantes con discapacidad y en general con necesidades educativas especiales. Las Administraciones educativas determinarán las medidas necesarias que garanticen el acceso y admisión de estos estudiantes a las enseñanzas universitarias oficiales de Grado en 
donde se establece el acceso a la enseñanza de grado desde los principios de igualdad y no discriminación y la accesibilidad de las pruebas de acceso para los estudiantes discapacitados o con necesidades especiales. Respecto de las pruebas de acceso este artículo será completado por el artículo $21^{[57]}$ el cual establece las medidas oportunas respecto de las comisiones organizadoras de las pruebas y los tribunales calificadores. Y el artículo $26^{[58]}$ del mismo que recoge el sistema de reserva de plazas para personas discapacitadas, siendo el $5 \%$ de las plazas ofertadas para estudiantes que tengan reconocido al menos el $33 \%$ de discapacidad.

\section{Real Decreto 592/2014, de 11 de julio, por el que se regulan las prácticas académicas externas de los estudiantes universitarios}

Las normas anteriormente contempladas se encuentran reflejadas, entre otras, en el Real Decreto 592/2014, de 11 de julio, por el que se regulan las prácticas académicas externas de los estudiantes universitarios.

condiciones de igualdad. Estas medidas podrán consistir en la adaptación de los tiempos, la elaboración de modelos especiales de examen y la puesta a disposición del estudiante de los medios materiales y humanos, de las asistencias y apoyos y de las ayudas técnicas que precise para la realización de las evaluaciones y pruebas que establezcan las Universidades, así como en la garantía de accesibilidad de la información y la comunicación de los procedimientos y la del recinto o espacio físico donde éstos se desarrollen. La determinación de dichas medidas se realizará en su caso en base a las adaptaciones curriculares que se aplicaron al estudiante en la etapa educativa anterior, para cuyo conocimiento las Administraciones educativas y los centros docentes deberán prestar colaboración".

57 Ibíd., artículo 21. Personas que presentan algún tipo de discapacidad:

"1. Las comisiones organizadoras de las pruebas de acceso determinarán las medidas oportunas que garanticen que los estudiantes que presenten algún tipo de discapacidad puedan realizar la prueba en las debidas condiciones de igualdad. En la convocatoria se indicará expresamente esta posibilidad.

2. Estas medidas podrán consistir en la adaptación de los tiempos, la elaboración de modelos especiales de examen y la puesta a disposición del estudiante de los medios materiales y humanos, de las asistencias y apoyos y de las ayudas técnicas que precise para la realización de la prueba de acceso, así como en la garantía de accesibilidad de la información y la comunicación de los procesos y la del recinto o espacio físico donde ésta se desarrolle.

3. Los tribunales calificadores podrán requerir informes y colaboración de los órganos técnicos competentes de las Administraciones educativas, así como de los centros donde hayan cursado estudios los estudiantes con discapacidad, que deberán informar de las adaptaciones curriculares realizadas".

58 Ibíd., artículo 26. Plazas reservadas a estudiantes con discapacidad: "Se reservará al menos un 5 por 100 de las plazas ofertadas para estudiantes que tengan reconocido un grado de discapacidad igual o superior al 33 por 100, así como para aquellos estudiantes con necesidades educativas especiales permanentes asociadas a circunstancias personales de discapacidad, que durante su escolarización anterior hayan precisado de recursos y apoyos para su plena normalización educativa.

A tal efecto, los estudiantes con discapacidad deberán presentar certificado de calificación y reconocimiento del grado de discapacidad expedido por el órgano competente de cada Comunidad Autónoma”. 
Varios artículos se encargan de regular aquellos aspectos que afectan al estudiante universitario discapacitado que quiere realizar prácticas externas; así, a modo de resumen hemos recopilado los preceptos que se refieren al colectivo de forma expresa.

En cuanto a los derechos del alumno que esté realizando prácticas se establece el derecho a la tutela, información, evaluación y desempeño de las prácticas en igualdad de condiciones. Además se le reconoce el derecho a la conciliación de estas prácticas con aquellas actividades o situaciones derivadas de la situación de discapacidad. Así queda recogido en su artículo $9^{[59]}$.

Referente a las tutorías y los tutores tanto de la propia Universidad como de la entidad en la cual se va a desarrollar la práctica del alumno discapacitado, se establece el derecho/deber de información, la posibilidad de solicitar los recursos necesarios para que el alumno discapacitado realice sus prácticas en igualdad de oportunidades, sin contravenir el principio de no discriminación y optando por la accesibilidad universal. Así mismo se establece el derecho de los tutores no sólo a recibir información sino también la formación necesaria para desempeñar esa función de tutorización del estudiante universitario discapacitado. Todo ello se recoge en los artículos 10 a 13 de la norma ${ }^{60}$.

59 Real Decreto 592/2014, de 11 de julio, por el que se regulan las prácticas académicas externas de los estudiantes universitarios, artículo 9. Relativo a los derechos y deberes de los estudiantes en prácticas:

“1. Durante la realización de las prácticas académicas externas, los estudiantes tendrán los siguientes derechos:

h) A disponer de los recursos necesarios para el acceso de los estudiantes con discapacidad a la tutela, a la información, a la evaluación y al propio desempeño de las prácticas en igualdad de condiciones.

i) A conciliar, en el caso de los estudiantes con discapacidad, la realización de las prácticas con aquellas actividades y situaciones personales derivadas o conectadas con la situación de discapacidad".

60 Real Decreto 592/2014, de 11 de julio, por el que se regulan las prácticas académicas externas de los estudiantes universitarios, artículo 10. Tutorías y requisitos para ejercerlas:

“... 4. Las universidades facilitarán a los tutores de estudiantes con discapacidad la información y la formación necesarias para el desempeño de esta función".

Artículo 12. Derechos y deberes del tutor académico de la universidad:

1. El tutor académico de la universidad tendrá los siguientes derechos:

“...g) Supervisar, y en su caso solicitar, la adecuada disposición de los recursos de apoyo necesarios para asegurar que los estudiantes con discapacidad realicen sus prácticas en condiciones de igualdad de oportunidades, no discriminación y accesibilidad universal".

Artículo 13. Informe de seguimiento intermedio e informe final del tutor de la entidad colaboradora:

"1.El tutor de la entidad colaboradora realizará y remitirá al tutor académico de la universidad un informe final, a la conclusión de las prácticas, que recogerá el número de horas realizadas por el estudiante y en el cual podrá valorar los siguientes aspectos referidos, en su caso, tanto a las competencias genéricas como a las específicas, previstas en el correspondiente proyecto formativo:

[...] d) Habilidades de comunicación oral y escrita. En el caso de estudiantes con discapacidad 
Por último, en cuanto a la oferta de las prácticas, estas han de cumplir varios criterios, entre los cuales se encuentran los de accesibilidad universal e igualdad de oportunidades. Así mismo se dará prioridad a este colectivo a la hora de elegir el lugar en el cual serán realizadas las prácticas para asegurar la accesibilidad no sólo en lo referido al organismo sino también del transporte. Ello en virtud del artículo $17^{[61]}$ apartados 1 y 3 .

\section{MEDIDAS DE ACCIÓN POSITIVA, IMPLEMENTACIÓN \\ DE LAS DISPOSICIONES NORMATIVAS A LA VISTA DE VARIOS \\ INFORMES SOBRE LA SITUACIÓN DE LAS UNIVERSIDADES \\ ESPAÑOLAS EN MATERIA DE DISCAPACIDAD}

Tras la breve aproximación a algunas de las normas que regulan aspectos que afectan a la vida y a los derechos del estudiante universitario con discapacidad debemos contemplar cómo se han llevado a cabo esas adaptaciones, recomendaciones y directrices en la Universidad. Ello lo haremos desde la base del "II Estudio sobre el grado de inclusión del Sistema Universitario Español respecto a la realidad de la Discapacidad"62 de la Fundación Universia, en colaboración con el CERMI, que aborda la situación más reciente de las 59 universidades intervinientes, con respecto a la discapacidad; sus datos pertenecen al curso 2013/2014. A modo de resumen hemos intentado recabar aquellos datos más interesantes que afectan al estudiante universitario discapacitado.

Hemos de partir del hecho de que el colectivo de alumnos universitarios discapacitados corresponden ${ }^{63}$ al 1,3\% de los estudiantes de grado (16.065, de los cuales el 50,9\% son hombres y el 49,1\% mujeres), al 1,2\% en estudios de postgrado (1.259, siendo el 54,4\% hombres y el $45,6 \%$ mujeres) y al $0,6 \%$ en doctorado (378, siendo un $49 \%$ hombres y un $51 \%$ mujeres), por lo que se denota una progresiva reducción de alumnos discapacitados a medida que avanzamos en el sistema universitario, continuando con la tendencia que se

que tengan dificultades en la expresión oral, deberá indicarse el grado de autonomía para esta habilidad y si requiere de algún tipo de recurso técnico y/o humano para la misma".

61 Ibíd., artículo 17. Oferta, difusión y adjudicación de las prácticas externas:

"1. Las universidades establecerán procedimientos de configuración de la oferta, difusión, solicitud y adjudicación de las prácticas externas de conformidad con criterios objetivos previamente fijados y garantizando, en todo caso, los principios de transparencia, publicidad, accesibilidad universal e igualdad de oportunidades.

[...] 3. Las universidades otorgarán prioridad a los estudiantes que realizan prácticas curriculares frente a los que solicitan prácticas extracurriculares. Asimismo se otorgará prioridad en la elección y en la adjudicación de prácticas a los estudiantes con discapacidad, con objeto de que puedan optar a empresas en las que estén aseguradas todas las medidas de accesibilidad universal, incluidas las referidas al transporte para su traslado y acceso a las mismas".

62 Disponible en: www.fundacionuniversia.net

63 II Estudio sobre el grado de inclusión del Sistema Universitario Español respecto a la realidad de la Discapacidad. Ver tablas 1 a 7, pp. 18 a 21. 
venía recogiendo en informes previos, como es el caso del Informe España 2013 "Derechos Humanos y Discapacidad" ${ }^{4}$.

Como hemos podido observar a lo largo del presente trabajo, existen varios aspectos que confluyen en la afección y disfrute al derecho a la educación superior, universitaria, desde la accesibilidad, la existencia de servicios de atención a personas discapacitadas, hasta derechos de participación o representación. Es por ello que nos vamos a detener en el estudio de alguno de estos aspectos.

En este sentido debemos ser conscientes de que en un $95 \%$ de las universidades participantes se dispone de un servicio ${ }^{65}$, programa o persona que se encarga de atender al colectivo de estudiantes discapacitados. Estos servicios de atención desempeñan diferentes funciones y se encargan de llevar a cabo distintos programas; entre los más ofertados encontramos ${ }^{66}$ :

- Programa y/o acciones curriculares de adaptación del puesto de estudio (software y hardware específico, mobiliario adaptado, reserva de asiento en las aulas, intérpretes de lengua de signos, entre otros) dirigida a los universitarios con discapacidad (95\%).

- Servicio de atención específica y especializada en materia de empleabilidad e inclusión laboral (80\%).

- Programa y/o acciones de tutorización y/o seguimiento de los estudiantes con discapacidad (80\%).

Entre los programas menos ofertados por los servicios de atención se encuentran:

- Acciones para fomentar la participación de estudiantes con discapacidad en los programas de movilidad nacional (27\%).

- Programa de asistencia personal permanente en sentido amplio dirigida a los universitarios con discapacidad (44\%).

Así mismo, en torno al $40 \%$ de los estudiantes con discapacidad indican que han acudido a los servicios principalmente para solicitar medidas ${ }^{67}$ de accesibilidad (34\%), información sobre sus derechos (32\%) y becas y ayudas $(31 \%)$. Los estudiantes universitarios con discapacidad proponen una serie de mejoras:

- Fomentar la mejora de la accesibilidad de espacios e instalaciones en general.

64 Informe España 2013 "Derechos Humanos y Discapacidad", elaborado por el CERMI, que en su página 40 recoge la citada tendencia: "El número de estudiantes con discapacidad va disminuyendo en las universidades españolas a medida que se continúa con la realización de estudios superiores".

65 II Estudio sobre el grado de inclusión del Sistema Universitario Español respecto a la realidad de la Discapacidad. Ver gráficos 1 y 2, pp. 26 y 27.

66 Ibíd., gráficos 11 y 12, pp. 34 y 36.

67 Ibíd., gráfico 41, p. 64. 
- Proporcionar un asesoramiento más específico adaptado al tipo de discapacidad.

- Apoyar y sensibilizar al profesorado ${ }^{68}$ y al resto de profesionales de la Universidad sobre cómo actuar.

- Contar con bolsas de empleo concretas para estudiantes con discapacidad.

Junto a esas mejoras propuestas por los alumnos debemos hablar de la existencia de varios problemas. Existe un problema o discrepancia entre los distintos servicios universitarios, y es la falta de comunicación entre los propios servicios y los interesados, como consecuencia, en parte, de la interpretación restrictiva que se hace de la Ley de Protección de Datos. Así mismo, otro problema podría ser el relativo a la financiación de los servicios ${ }^{69}$ : en torno al $42 \%$ destinan una cuantía que oscila entre los 0 y los $30.000 €$ (una horquilla muy amplia, a nuestro juicio, e insuficiente) y de esa financiación ${ }^{70}$ gran parte proviene de financiación privada y donaciones (47\%), habiéndose producido un descenso respecto de la financiación pública ${ }^{71}$; cuestión que ha podido derivar en la búsqueda y cooperación con otras entidades sin ánimo de lucro, de las que se nutren de recursos materiales y/o personales. Además de lo anterior se ha detectado en el informe un problema relativo a la evaluación del servicio de atención ${ }^{72}$; en ese aspecto la deficiencia que se deduce es que la mayoría de las universidades no implementan un sistema de evaluación (39\%), seguidamente cuentan con un sistema de gestión propio (36\%) y tan sólo el $8 \%$ cuentan con un sistema independiente obtenido por una norma de calidad UNE-EN ISO9001; junto a ello hemos de señalar que se producen discrepancias o diferencias, en el informe, dependiendo de quién suministra información, el servicio de atención o el alumnado.

En cuanto al conjunto de los servicios de atención a las personas con discapacidad, hemos de abogar por la implementación de los mismos, vía normativa, en todas las universidades, siendo la financiación proveniente, principal y fundamentalmente, de recursos públicos, consecuencia de la implementación de las competencias respectivas derivadas de la Convención e incorporadas en el ordenamiento interno. Así mismo es importante que la evaluación de su actividad sea realizada de forma externa y preferiblemente con normas de calidad reconocidas, por ejemplo las normas iso.

68 Profundizar en Moriña-Díez, A.; López Gavira, R.; Melero Aguilar, N.; Cortés Vega, M. D. y Molina Romo, V. M. (2013). El profesorado en la Universidad ante el alumnado con discapacidad: ¿tendiendo puentes o levantando muros? Revista de Docencia Universitaria. REDU. vol. 11 (3) octubre-diciembre, 423-442. Recuperado el 01/02/2015 en: http://www.red-u.net/

69 II Estudio sobre el grado de inclusión del Sistema Universitario Español respecto a la realidad de la Discapacidad. Ver gráficos 8 y 9, p. 32.

70 Ibíd., gráfico 17, p. 41.

71 Ibíd., gráficos 50 y 51, p. 75.

72 Ibíd., gráfico 15, p. 39. 
Es igualmente importante tomar en consideración la accesibilidad; habiendo de reconocer el importantísimo cambio sufrido desde la implantación de las nuevas titulaciones, momento a partir del cual se ha reformado la Universidad y se ha aprovechado para incorporar la adaptación de los planes de accesibilidad al modelo de accesibilidad universal y diseño para todos, la adaptación de los planes de estudio a la variable discapacidad, la formación del profesorado y personal de la Universidad, etc.

En este sentido, el 58\% de las universidades integrantes han implementado planes de accesibilidad ${ }^{73}$ universal y diseño para todos, y de ese porcentaje el $15 \%$ lo han realizado con un sistema global certificado por norma ISO: UNE 17001-2. Esos planes de accesibilidad se han dado en varias áreas:

- Tecnologías de la información y comunicación ${ }^{74}$ : el certificado de accesibilidad de las páginas web, Web Accesibility Initiative (WAI), es contenido por el $48 \%$ de las páginas web de las universidades y por el $31 \%$ de los campos virtuales.

- Transporte ${ }^{75}$ : en el $92 \%$ existe la posibilidad de acceso mediante transporte público, si bien tan sólo un $14 \%$ cuenta con transporte propio adaptado.

- Instalaciones e infraestructuras ${ }^{76}$ : en cuanto a la existencia de productos de apoyo en instalaciones e infraestructuras universitarias, el $31 \%$ cuenta con bucles magnéticos, el $31 \%$ con avisos sonoros, el $34 \%$ con avisos visuales, con lo que existe una mayoría que no dispone de estos. Así mismo, respecto de las residencias universitarias (propiedad de la universidad) suele darse prioridad a la persona discapacitada (41\%).

- Ocio y deporte ${ }^{77}$ : este aspecto es preocupante debido a los datos facilitados; en el $73 \%$ no se llevan a cabo actividades deportivas inclusivas.

Las universidades han de realizar esfuerzos en cuanto a la accesibilidad, pues varias son las deficiencias que existen, fundamentalmente en productos de apoyo en infraestructuras e instalaciones, así como en la las prácticas inclusivas de las actividades, principalmente, deportivas. Respecto de las instalaciones e infraestructuras, estas son la primera causa de queja, por no ser accesibles, que presentan los alumnos discapacitados $(41 \%)^{78}$. Otro de los aspectos a reseñar negativamente es la financiación ${ }^{79}$, pues el total de los fondos recibidos, según consta en el informe, es de $260.096 €$, de los cuales 196.817 han sido aportados por entidades privadas.

73 II Estudio sobre el grado de inclusión del Sistema Universitario Español respecto a la realidad de la Discapacidad, ver gráficos 21, 21.1 y 21.2, pp. 46 y 47.

74 Ibíd., gráficos 22, 22.1, 22.2, 23, 23.1 y 23.2, pp. 47 a 49.

75 Ibíd., gráficos 24,25 y 26, pp. 50 y 51.

76 Ibíd., gráficos 28 y 29 , pp. 52 y 53.

77 Ibíd., gráficos 30 y 30.1, p. 53.

78 Ibíd., gráfico 47, p. 67.

79 Ibíd., gráficos 31, 31.1 y tabla 19, pp. 54 y 55. 
Respecto de la adaptación y diseño de los planes de estudio ${ }^{80}$, en torno a la mitad de las universidades participantes, el 51\%, ha incorporado la variable discapacidad en el diseño de los mismos, si bien el $22 \%$ no ha avanzado en este aspecto, y en el mismo porcentaje se afirma que se ha tenido en cuenta para determinados grados, siendo estos el perfil ${ }^{81}$ universitario mayoritario de los estudiantes con discapacidad (ciencias sociales y jurídicas e ingeniería). La crítica a la adaptación y diseño de los planes de estudio viene referida a la no existencia de una estandarización en el modo y manera de implementar, lo cual deriva en una diferenciación entre las universidades.

En cuanto a la formación del profesorado y de voluntarios como apoyo a esa accesibilidad, 3.638 profesores y 1.547 voluntarios han recibido formación y sensibilización ${ }^{82}$. Así mismo, respecto del profesorado, hemos de realizar una crítica que traslada el alumnado discapacitado y referida a que son los propios alumnos discapacitados quienes informan de su situación al docente $^{83}(75 \%)$, produciéndose una gran discrepancia con los datos aportados por los servicios $(45+5)$.

Las adaptaciones ${ }^{84}$ recibidas varían en función de la tipología de discapacidad, pudiendo darse desde la digitalización de textos hasta adaptaciones curriculares en las materias o reserva de asientos en el aula. Así mismo, entre las mayores dificultades que encuentran estos alumnos, un $27 \%{ }^{85}$ señala el material facilitado por los docentes, lo que hace necesario un mayor esfuerzo proveniente no sólo del docente sino de la propia Universidad que ha de formarlo y concienciarlo para que en un futuro este porcentaje se reduzca considerablemente.

\section{REFLEXIÓN}

Para concluir con el presente estudio hemos de señalar varias ideas que condensan nuestro trabajo.

Se ha producido el tránsito del concepto de discapacidad, desde una visión médico-asistencial, propia de las primeas décadas, a una visión ocupada en la garantía de los derechos y la protección de valores y principios, entre los que resaltan la igualdad, efectiva y real, la no discriminación, y el acceso, diseño universal y para todos, tras la suscripción de la Convención sobre los Derechos de las Personas con Discapacidad.

80 Ibíd., gráfico 32, p. 56.

81 Ibíd., tablas 2 a 7, pp. 19 a 21.

82 II Estudio sobre el grado de inclusión del Sistema Universitario Español respecto a la realidad de la Discapacidad, ver tabla 20, p. 57.

83 Ibíd., gráficos 45, p. 66.

84 Ibíd., gráfico 44, p. 65.

85 Ibíd., gráfico 47, p. 67. 
Respecto del iter normativo, en las primeras etapas las diferentes normas apenas contenían especificaciones referidas al disfrute de derechos y a las garantías de los mismos, si bien tras la ratificación por distintos Estados, entre ellos España, de la Convención sobre los Derechos de las Personas con Discapacidad se produce un salto cualitativo en la positivación no sólo de los derechos y principios, sino también de las medidas de acción positivas que habrían de ser contenidas en la legislación de los Estados parte. Ello sucedería así en España, aprobándose desde entonces una pluralidad de normas tendentes a dar cumplimiento a los compromisos adquiridos tras la firma y ratificación de la Convención.

Se evidencia la necesidad de seguir en el camino que han iniciado las universidades y complementarlo con el fomento en investigación tanto en proyectos propios y/o tesis, como en trabajos de fin de grado o máster, desde la perspectiva no sólo básica sino aplicada de esas investigaciones. Así como la oportunidad de fomentar medidas y políticas activas tendentes a la consecución del incremento del número de alumnos con discapacidad que accedan y se mantengan en las enseñanzas universitarias. Fomentando igualmente programas de formación en el ámbito de la discapacidad tanto del profesorado como de la comunidad universitaria en general, para que de ello se derive una adecuada respuesta a las necesidades del colectivo de estudiantes discapacitados.

La crisis económica ha tenido como consecuencia la disminución de la financiación de las universidades, reflejada en los niveles de prestación de ayudas complementarias a la exención y/o reducción en el pago de la matrícula, así como en la adaptación y compra de materiales de apoyo necesarios para lograr la accesibilidad del alumno, en la prestación de programas y realización de tareas. Es por ello que se debe fortalecer la colaboración entre administraciones públicas y organismos públicos y privados para conseguir no sólo un aumento de la financiación, sino también una mayor eficacia y eficiencia de recursos materiales y humanos.

En cuanto a la modificación de la normativa interna universitaria, respecto de los estatutos universitarios es de criticar que en su mayoría se remitan a la legislación vigente, de mínimos, no aprovechando la oportunidad para regular las distintas facetas del personal con discapacidad o que interactúa con estudiantes discapacitados, y no definiendo en profundidad los servicios de atención a personas/estudiantes con discapacidad; en el mismo sentido cabe criticar la falta de reglamentos específicos de estudiantes universitarios que regulen este aspecto en profundidad y que se comprometan a regular tanto los derechos como las obligaciones del colectivo de estudiantes discapacitados.

Por último, es preciso referirse al concepto de "ajustes razonables", entendidos como garantía y como derecho subjetivo. En cuanto garantía, los ajustes razonables se refieren a la protección de los derechos de igualdad y no discriminación, haciendo por lo tanto factibles el acceso y disfrute de 
derechos de forma plena y efectiva con el único límite de la carga desproporcionada y/o indebida. Es decir, afianzan la eficacia de los derechos. En cuanto derecho subjetivo nacido de la Convención y positivado en el ordenamiento interno, es preciso destacar su configuración como un concepto jurídico indeterminado, con la consiguiente necesidad de su especificación en cada caso o en cada colectivo y situación. Si bien se precisa de una mayor concreción normativa en las diferentes esferas de aplicación, siendo necesarios criterios orientadores que no agoten la aplicación subjetiva del ajuste razonable en función del caso concreto, pero que en todo caso ayuden a su seguridad o a la garantía del mismo. Puesto que hasta ahora podemos hacer cierta arquitectura para configurar el concepto de ajustes razonables con el derecho a la educación en relación con los pronunciamientos del Tribunal Constitucional al tratarse la educación de un derecho fundamental, así una medida restrictiva al mismo habrá de superar el juicio de proporcionalidad en su triple dimensión: "juicio de idoneidad", "juicio de necesidad" y "juicio de proporcionalidad stricto sensu". Estos tres requisitos habrán de estar motivados y razonados, y la Administración deberá igualmente motivar la desproporcionalidad de la carga que podría ir relacionado con la "atención individualizada" que requiera la presencia de pocos alumnos, con una organización de la asignatura o lección muy pendiente del estudiante en el sentido de diferenciada/especial.

\section{REFERENCIAS BIBLIOGRÁFICAS}

Alonso Seco, J. M. et al. (1992). Desarrollo y aplicación de la LiSMI (1982-1992) (2. ed.). Madrid: Secretaría General del Real Patronato de Prevención y de Atención a Personas con Minusvalía.

Cayo Pérez Bueno, L. "La configuración jurídica de los ajustes razonables”. Disponible en: www.coag.es

Moriña-Diez, A.; López Gavira, R.; Melero Aguilar, N.; Cortés Vega, M. D. y Molina Romo, V. M. (2013). El profesorado en la universidad ante el alumnado con discapacidad: ¿tendiendo puentes o levantando muros? Revista de Docencia Universitaria. REDU. vol. 11 (3) octubre-diciembre, 423-442. Recuperado el 01/02/2015 en http://www.red-u.net/

Moswela, E. y Mukhopadhyay, S. (2011). Asking for too much? the voices of students with disabilities in botswana. Disability \& Society, 26(3), 307-319. doi:10.1080/0968 7599.2011.560414.

\section{Otros documentos}

II Estudio sobre el grado de inclusión del Sistema Universitario Español respecto a la realidad de la Discapacidad. Disponible en: www.fundacionuniversia.net

Informe España 2013 “Derechos Humanos y Discapacidad”, elaborado por el CERMI. 


\section{Normativa}

Española

Anteproyecto de Constitución Española: Boletín Oficial de las Cortes de 5 de enero de 1978, n. $^{\circ} 44$.

Constitución Española de 1978.

Ley 13/1982, de 7 de abril, de Integración Social de los Minusválidos.

Ley Orgánica 1/1990, de 3 de octubre, de Ordenación General del Sistema Educativo.

Ley Orgánica 6/2001, de 21 de diciembre, de Universidades.

Ley 51/2003, de 2 de diciembre, de igualdad de oportunidades, no discriminación y accesibilidad universal de las personas con discapacidad (LIONDAU).

Ley Orgánica 4/2007, de 12 de abril, por la que se modifica la Ley Orgánica 6/2001, de 21 de diciembre, de Universidades.

Ley 49/2007, de 26 de diciembre, por la que se establece el régimen de infracciones y sanciones en materia de igualdad de oportunidades, no discriminación y accesibilidad universal de las personas con discapacidad.

Ley 26/2011, de 1 de agosto, de adaptación normativa a la Convención Internacional sobre los Derechos de las Personas con Discapacidad.

Real Decreto 1276/2011, de 16 de septiembre, de adaptación normativa a la Convención Internacional sobre los Derechos de las Personas con Discapacidad.

Real Decreto Legislativo 1/2013, de 29 de noviembre, por el que se aprueba el Texto Refundido de la Ley General de derechos de las personas con discapacidad y de su inclusión social.

Real Decreto 412/2014, de 6 de junio, por el que se establece la normativa básica de los procedimientos de admisión a las enseñanzas universitarias oficiales de Grado.

Real Decreto 592/2014, de 11 de julio, por el que se regulan las prácticas académicas externas de los estudiantes universitarios.

\section{Internacional}

Declaración Universal de los Derechos Humanos (DUDH).

Pacto Internacional de Derechos Civiles y Políticos.

Protocolo Adicional al Convenio para la Protección de los Derechos Humanos y de las Libertades Fundamentales, de 20 de marzo de 1952.

Convención sobre los Derechos de las Personas con Discapacidad de las Naciones Unidas. 


\section{Unión Europea}

Carta de Derechos Fundamentales de la Unión Europea (CDFUE).

Normas Uniformes sobre Igualdad de Oportunidades para las Personas con Discapacidad [A/RES/48/96].

Jurisprudencia del Tribunal Constitucional

STC 5/1981.

STC 6/1982.

STC 77/1985.

STC $14 / 2004$.

STC 236/2007, de 7 de noviembre.

STC 111/2012.

STC 214/2012.

STC 10/2014, de 27 de enero. 